\title{
Development of a porcine skeletal muscle cDNA microarray: analysis of differential transcript expression in phenotypically distinct muscles \\ Qianfan Bai ${ }^{1}$, Christine McGillivray ${ }^{1}$, Nuno da Costa1, Saffron Dornan², Gary Evans $^{2}$, Michael James Stear ${ }^{1}$ and Kin-Chow Chang*1
}

Address: ${ }^{1}$ Laboratory of Veterinary Molecular Medicine, Department of Veterinary Pathology, University of Glasgow, Bearsden Road, Glasgow G61 $1 \mathrm{QH}, \mathrm{UK}$ and ${ }^{2}$ Sygen International, Department of Pathology, University of Cambridge, Tennis Court Road, Cambridge CB2 1QP, UK

Email: Qianfan Bai - 9912270b@student.gla.ac.uk; Christine McGillivray - cph1u@udcf.gla.ac.uk; Nuno da Costa - nadc1a@udcf.gla.ac.uk; Saffron Dornan - scd@mole.bio.cam.ac.uk; Gary Evans - evans@fyf.pig.co.uk; Michael James Stear - m.j.stear@vet.gla.ac.uk; KinChow Chang* - k.chang@vet.gla.ac.uk

* Corresponding author

(C) 2003 Bai et al; licensee BioMed Central Ltd. This is an Open Access article: verbatim copying and redistribution of this article are permitted in all media for any purpose, provided this notice is preserved along with the article's original URL.

\begin{abstract}
Background: Microarray profiling has the potential to illuminate the molecular processes that govern the phenotypic characteristics of porcine skeletal muscles, such as hypertrophy or atrophy, and the expression of specific fibre types. This information is not only important for understanding basic muscle biology but also provides underpinning knowledge for enhancing the efficiency of livestock production.

Results: We report on the de novo development of a composite skeletal muscle cDNA microarray, comprising 5500 clones from two developmentally distinct cDNA libraries (longissimus dorsi of a 50day porcine foetus and the gastrocnemius of a 3-day-old pig). Clones selected for the microarray assembly were of low to moderate abundance, as indicated by colony hybridisation. We profiled the differential expression of genes between the psoas (red muscle) and the longissimus dorsi (white muscle), by co-hybridisation of $\mathrm{Cy} 3$ and $\mathrm{Cy} 5$ labelled cDNA derived from these two muscles. Results from seven microarray slides (replicates) correctly identified genes that were expected to be differentially expressed, as well as a number of novel candidate regulatory genes. Quantitative real-time RT-PCR on selected genes was used to confirm the results from the microarray.
\end{abstract}

Conclusion: We have developed a porcine skeletal muscle cDNA microarray and have identified a number of candidate genes that could be involved in muscle phenotype determination, including several members of the casein kinase 2 signalling pathway.

\section{Background}

Skeletal muscle is a heterogeneous tissue that has the ability to rapidly undergo biochemical and physical changes in response to external stimuli, such as appropriate nervous and hormonal stimulations, to adapt to the accompa- nying functional demands imposed on it. There is wide variation in phenotype between anatomical muscles in the body. Postural muscles, often described as red muscles, such as the soleus and psoas in the pig, are under continuous but modest activation. They are adapted to 
undertake chronic contractile activity without fatigue, under aerobic respiratory conditions. On the other hand, white muscles, such as the gastrocnemius and longissimus dorsi, are recruited sporadically during brief periods of intense muscular activity, like running. They are susceptible to fatigue as their main source of energy is derived from anaerobic glycolysis. Red muscles are better endowed with capillaries, myoglobin, lipids and mitochondria than white muscles $[1,2]$. Red and white muscles also differ in their fibre type composition. Postnatal mammalian muscles (e.g. in pigs and rodents) have 4 major fibre types characterised by the expression of the slow $/ \beta, 2 a, 2 x$ and $2 \mathrm{~b}$ myosin heavy chain (MyHC) gene isoforms [2-4]. Based on MyHC isoform expression, postnatal muscle fibres in the pig have recently been resolved by the combination of immunocytochemistry and in situ hybridisation into 4 major types [5-7]. Metabolic, biochemical and biophysical characteristics, such as oxidative and glycolytic capacities, fibre size, colour, and glycogen and lipid contents, vary between MyHC fibre types $[2,8,9]$. The slow $/ \beta$ and fast $2 \mathrm{~b}$ fibres, also known as slow oxidative and fast glycolytic respectively, represent two extreme metabolic profiles. The fast $2 \mathrm{a}$ and fast $2 \mathrm{x}$ fibres are intermediate fast oxidative-glycolytic fibres. Fast 2 a fibres are more closely related to slow/I fibres, and fast $2 \mathrm{x}$ are more similar to fast $2 b$ fibres. Hence the composition of fibre types in a muscle is a major determinant of its phenotypic properties.

Understanding the molecular processes that govern the phenotypic characteristics of muscles, such as hypertrophy/atrophy, and expression specific fibre types, is of agricultural and medical importance [9-12]. Microarray technology can simultaneously measure the differential expression of a large number of genes in a given tissue and may identify the genes responsible for the relevant phenotype [13]. We report here on the de novo development of a porcine skeletal muscle cDNA microarray, comprising 5500 clones from two cDNA muscle libraries. Its functional integrity was assessed by profiling the differences in gene expression between red (psoas) and white (longissimus dorsi, LD) muscles. Among the differentially expressed genes, a number of novel candidate genes were found that could determine the phenotypic differences among different muscle types.

\section{Results \\ Construction of a composite porcine skeletal muscle cDNA microarray}

The de novo development of a porcine skeletal muscle cDNA microarray was based on the use of two representative, directionally cloned $\lambda$ ZAP-Express cDNA expression libraries; one derived from the back muscle of a 50-dayold foetus and the other from the gastrocnemius of a 3-dayold pig. Genes that are expressed in skeletal muscle are likely to be present in one or both libraries. In our porcine skeletal muscle cDNA libraries, about a third of the clones were found to be from highly expressed genes, based on signal intensity of hybridisation (Fig. 1A). Weakly to moderately expressed genes were selected for microarray assembly; highly expressed clones were avoided (Fig. 1B). On average, between a quarter and a half of the randomly picked colonies from each square agar plate were eventually selected for microarray assembly. A total of 5,500 plasmid clones were selected, of which 3,500 clones were taken from the 3-day-old muscle library and 2,000 clones were taken from the 50-day foetal muscle library. After each production step of miniprep plasmid preparation, insert amplification, and PCR product purification, about a quarter of the selected clones were checked by gel electrophoresis or spectrophotometry. Approximately $10 \%$ of all selected clones were found to be without any cDNA insert, a figure expected in a typical cDNA library (data not shown). Each selected clone was printed twice on the microarray (Fig. 2A).

\section{Functional assessment of the porcine cDNA microarray: red-white muscle analysis}

To evaluate the performance of our composite porcine skeletal muscle cDNA microarray, a profiling experiment was conducted to determine the differential expression of genes between red (psoas) and white (longissimus dorsi, LD) muscle. Dual-colour hybridisation (Fig. 2A) was performed on seven replicate microarray slides. An intensitydependent (LOWESS) step was used to normalise data. Fig. $2 \mathrm{~B}$ plots the median expression of each clone in the psoas against the median expression of the same clone in the $\mathrm{LD}$ muscle. Each point is the median of 14 values (2 replicates per slide, 7 slides per muscle). Most points cluster around the middle line indicating similar levels of expression in both muscles. There were, however, a number of clones falling substantially below the line, indicating consistently lower levels of expression in the psoas compared with the LD muscle. Low signal readings for both dyes may indicate the absence of a cDNA insert. About $12 \%$ of the printed clones were found to fall below 50 units for both dyes and were considered to be without cDNA inserts. This value was consistent with the earlier estimate of insertless clones in the cDNA libraries.

A normalised psoas/LD ratio of 2.0 or more was used to identify genes that were more highly expressed in psoas than in LD muscle. This ratio represents the top $5 \%$ of differences in expression. Seventy clones meeting this criterion were sequenced. The sequences were compared with database sequences by BLAST searching. Table 1 is a summary of these genes. Sixty seven percent of the clones ( 47 out of 70) sequenced were genes of mitochondrial origin. Of these several were featured more than once on the microarray, namely genes encoding $16 \mathrm{~S}$ ribosomal RNA, $12 \mathrm{~S}$ ribosomal RNA, and NADH dehydrogenase subunits 


\section{A. Unselected B. Selected}

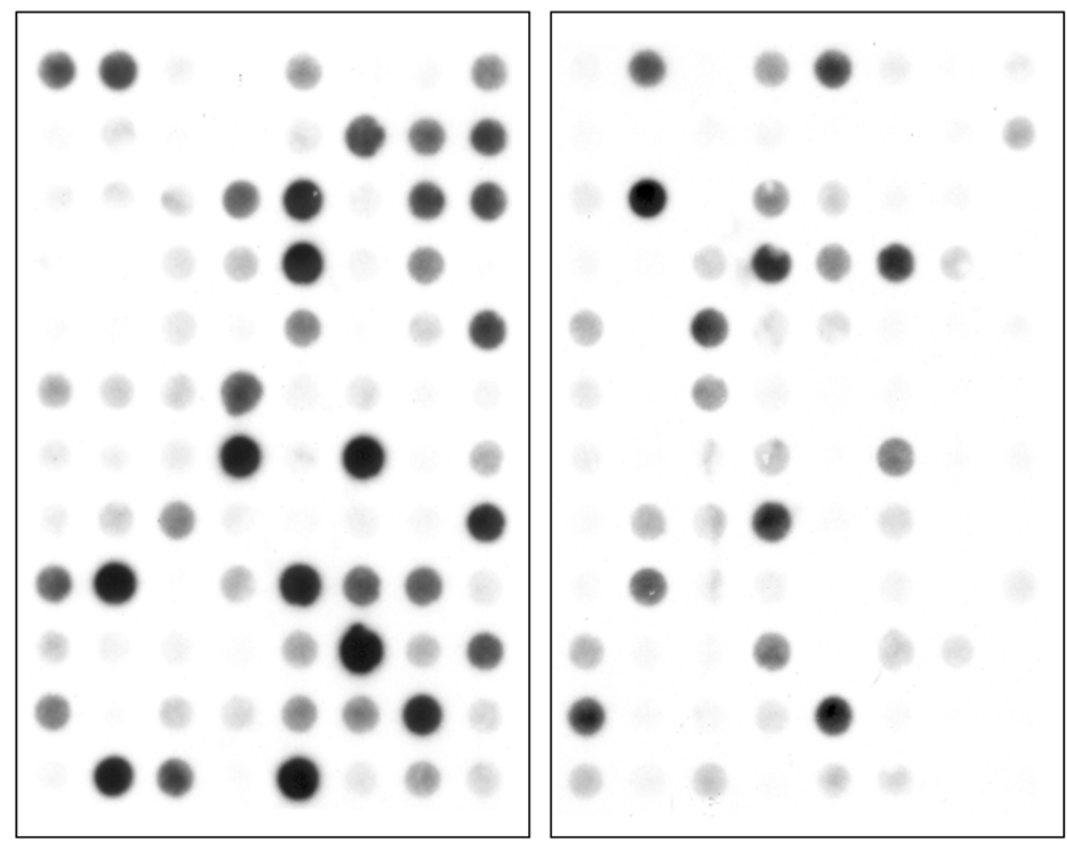

\section{Figure I}

Selection of clones for porcine skeletal muscle cDNA microarray assembly by colony hybridisation. A. A typical colony dotblot hybridisation result of randomly selected plasmid clones, from a 50-day-old foetal back muscle cDNA library, probed with 32P-labelled total cDNA, derived from the same muscle of a 50-day-old foetus. B. A typical hybridisation result of selected plasmid clones, assessed by previous hybridisation $(\mathbf{A})$ to be from weakly to moderately expressed genes. A reduction in the number of highly expressed clones could be seen in panel $B$.

3 and 6 . Thirty percent of the clones (21 out of 70 ) did not show any homology with known mitochondrial or sarcomeric genes. The function of 9 of these clones was completely unknown. One gene encoded for fructose-1,6biphosphatase, an enzyme that is necessary for muscle gluconeogenesis. The function of the remaining 11 clones were involved with aspects of transcription, translation or signal transduction, but their functions in skeletal muscle have not been characterised. Several genes were members of the casein kinase 2 signalling pathway. The $\alpha 1$ subunit of casein kinase 2 (CK2) is one half of the holoenzyme $[14,15]$. The small muscle protein (smpx) is encoded by a recently discovered X-linked stretch response gene [16].
The tyrosine kinase A6-related protein binds ATP and actin, and interacts with protein kinase $\mathrm{C}$ zeta [17]. Although the function of the latter two proteins is not known, both were shown to be targets of CK2 phosphorylation.

Clones with a normalised psoas/LD ratio of 0.7 or less, which represented the most extreme 5\% of clones were identified. Forty-five clones were sequenced and examined for homology by BLAST searching. Table 2 lists the genes that were more highly expressed in the LD than in the psoas. Only 4 out of 45 clones were of mitochondrial origin, and they were different from those expressed more 
A.

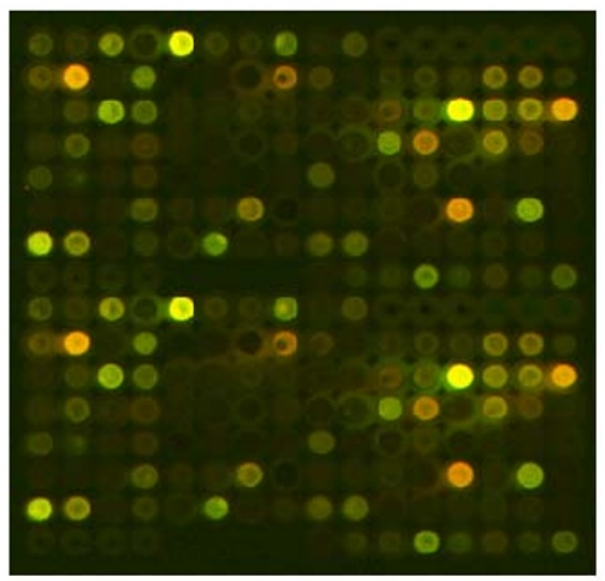

Psoas $=\mathrm{Cy} 3 ; \mathrm{LD}=\mathrm{Cy} 5$
B.

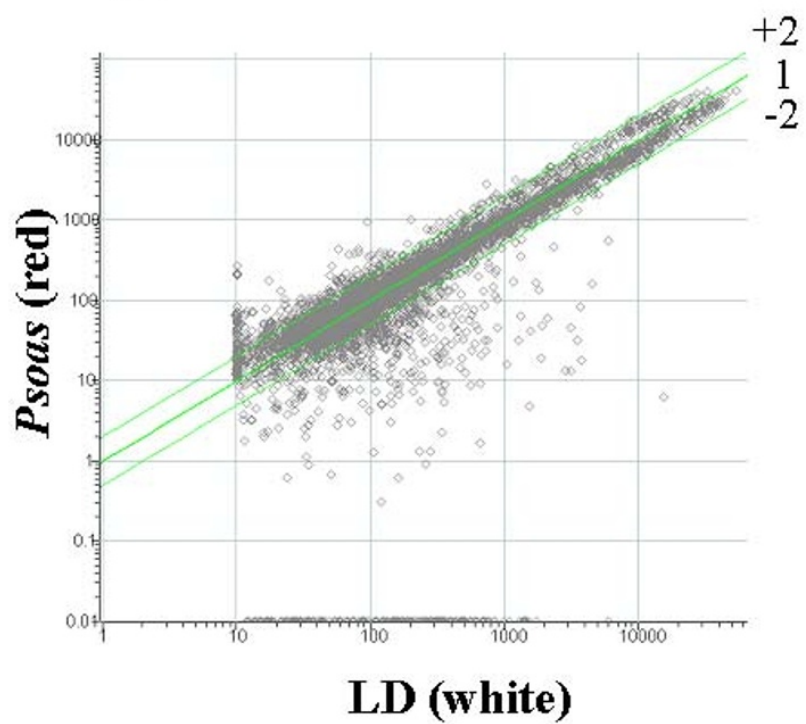

Figure 2

Differential gene expression between red and white porcine muscles. A. An illustration of a two-colour hybridisation. There were 48 such grids on each microarray slide. Each clone was printed twice. Clones on the top half were duplicated in the lower half of each grid. With some spots, the surrounding background was higher than the signal of the corresponding spots. B. Scatter plot displaying the median expression profile of all genes represented on the microarray, based on seven replicate slides. Genes equally expressed in red and whites would be positioned along the middle line (I). Points above the +2 or below -2 represent genes that were at least 2 -fold more or less highly expressed in the psoas than the LD.

abundantly in the psoas (Table 1). Fast isoforms of sarcomeric proteins (myosin heavy chains [MyHCs] 2a, 2x, 2b, myosin regulatory light chain $2, \alpha$-actinin 3 , fast troponin $\mathrm{C}$, and fast troponin T3) were well represented amongst the sequenced clones. Sarcomeric/structural genes made up nearly half of the total clones ( 22 out of 45 ). The other highly represented group of genes on the list ( 11 out of 45 clones) were involved in glycolysis, such as glyceraldehyde 3-phosphate dehydrogenase (GAPDH). The function of two non-sarcomeric genes was completely unknown. A few candidate regulatory genes (bin1, polyubiquitin, myomegalin-like, and HSPA8) were also found. Of particular interest is the tumour suppressor gene bin 1 [18], which has recently been shown to play a role in C2C12 myoblast differentiation [19].

\section{Quantitative expression of selected genes: validation by TaqMan real time RT-PCR}

To assess the validity of the microarray approach to identify differentially expressed genes, quantitative real-time RT-PCR (TaqMan) was performed on four representative clones, GAPDH, MyHC 2b, bin1, and a novel gene (kc2725), each normalised to $\beta$-actin. In line with functional expectations, recent quantitative work performed has shown that the mRNA expression of GAPDH and MyHC 2b was higher in the psoas than in the LD within individual animals [20]. In this study, the relative levels of GAPDH and MyHC $2 \mathrm{~b}$ of pooled total cDNA samples from three 22-week-old Berkshire pigs were measured (Fig. 3). Our results showed that the differential expression of GAPDH and MyHC 2b was sufficiently consistent between the two muscles to be detected in pooled cDNAs. A novel gene kc2725 of unknown function, found by 
Table I: Genes more highly expressed in psoas than in LD

\begin{tabular}{|c|c|c|c|c|}
\hline Gene & Psoas/LD & Homology & \# of clones & Accession \# \\
\hline \multicolumn{5}{|l|}{ Mitochondrial origin } \\
\hline I6S ribosomal RNA & 2.07 & $97 \%(S)$ & 12 & AY0III78 \\
\hline I $2 \mathrm{~S}$ ribosomal RNA & 2.18 & $100 \%(S)$ & 7 & AY0I2I45 \\
\hline $28 \mathrm{~S}$ ribosomal RNA & 2.67 & $99 \%(R)$ & I & V0I 270 \\
\hline Ribosomal protein S29 & 4.14 & $94 \%(B)$ & 1 & U66372 \\
\hline Ribosomal protein L23 & 30.05 & $92 \%(\mathrm{H})$ & 1 & NM_000978 \\
\hline Cytochrome oxidase subunit I & 2.03 & $86 \%(B)$ & 2 & AF490529 \\
\hline Cytochrome oxidase subunit III & 2.28 & $81 \%(T)$ & 1 & AF030272 \\
\hline Cytochrome oxidase subunit VIc & 27.97 & $88 \%(\mathrm{H})$ & 1 & NM_004374 \\
\hline Cytochrome oxidase subunit VIb & 2.51 & $96 \%(B)$ & I & $\times 15112$ \\
\hline NADH dehydrogenase subunit 2 & 2.51 & $77 \%(P)$ & 1 & AF4I4I2I \\
\hline NADH dehydrogenase subunit 3 & 2.58 & $82 \%(B)$ & 7 & AY05263I \\
\hline NADH dehydrogenase subunit 6 & 2.15 & $81 \%(B)$ & 4 & AF4I645I \\
\hline $\mathrm{NADH}$ dehydrogenase subunit $\mathrm{BI} 5$ & 2.34 & $87 \%(B)$ & I & X64898 \\
\hline ATP synthase protein 6 & 2.1 & $96 \%(S)$ & 2 & AFI908I3 \\
\hline ATP synthase protein 8 & 2.17 & $100 \%(S)$ & i & AF039170 \\
\hline ATP synthase protein 9 & 20.55 & $96 \%(H)$ & 1 & NM_00I689 \\
\hline tRNA & 3.87 & $97 \%(S)$ & 2 & AF304202 \\
\hline Adenine nucleotide translocator SLC25A6 & 2.05 & $92 \%(\mathrm{H})$ & 1 & XM_II4724 \\
\hline \multicolumn{5}{|l|}{ Sarcomeric / structural } \\
\hline Ankyrin I & 2.23 & $93 \%(\mathrm{H})$ & 1 & XM_0I6774 \\
\hline Tubulin alpha I & 2.68 & $94 \%(\mathrm{H})$ & 1 & $\mathrm{AFI} 4 \mathrm{I} 347$ \\
\hline \multicolumn{5}{|l|}{ Non-sarcomeric } \\
\hline $\begin{array}{l}\text { Pituitary tumor-transforming I interacting } \\
\text { protein (tr) }\end{array}$ & 2.98 & $84 \%(\mathrm{H})$ & 1 & ВС031097 \\
\hline $\begin{array}{l}\text { Par-6 partitioning defective } 6 \text { homolog } \\
\text { gamma (tr) }\end{array}$ & 30.36 & $92 \%(M)$ & I & XM_I29044 \\
\hline $\begin{array}{l}\text { TAFIII 40, a novel TAF component (TATA- } \\
\text { binding protein associated factors) (tr) }\end{array}$ & 2.16 & $94 \%(\mathrm{H})$ & 1 & AJ292190 \\
\hline STAF transcriptional activator (tr) & 2.15 & $88 \%(\mathrm{H})$ & 1 & NM_003442 \\
\hline Prefoldin subunit 6 (KE2 protein) (tl) & 2.65 & $85 \%(M)$ & 1 & M65255 \\
\hline EH domain-binding protein, Epsin (s) & 2.23 & $93 \%(H)$ & 2 & NM_013333 \\
\hline Beta-catenin (s) & 2.18 & $100 \%(S)$ & 1 & $A B 046|7|$ \\
\hline Casein kinase 2, alpha I polypeptide (s) & 6.47 & $87 \%(H)$ & 1 & NM_001895 \\
\hline Small muscle protein (smpx) (s) & 7.34 & $88 \%(\mathrm{H})$ & i & BC005948 \\
\hline $\begin{array}{l}\text { Tyrosine kinase 9-like (A6-related protein) } \\
\text { (s) }\end{array}$ & 2.04 & $90 \%(\mathrm{H})$ & 1 & $\mathrm{BC} 016452$ \\
\hline Fructose-1,6-biphosphatase (m) & 25.07 & $92 \%(O)$ & 1 & AJ272520 \\
\hline $\begin{array}{l}\text { Testis intracellular mediator protein } \\
\text { (PEAS) (u) }\end{array}$ & 2.12 & $88 \%(H)$ & 1 & $\mathrm{BC} 021546$ \\
\hline Hypothetical protein (FLJI2666) (u) & 2.23 & $93 \%(H)$ & 1 & NM_024595 \\
\hline Unknown small protein (u) & 3.93 & $94 \%(H)$ & 1 & BC005398 \\
\hline $\begin{array}{l}\text { Unknown clone (kc2725), homologous to } \\
\text { 3' untranslated region (UTR) of *RNA } \\
\text { binding protein SI (u) }\end{array}$ & 2.57 & $* 90 \%(\mathrm{H})$ & 1 & *XM_028847 \\
\hline $\begin{array}{l}\text { Unknown clone, homologous to 3' UTR of } \\
\text { *enhancer of rudimentary }(\mathrm{u})\end{array}$ & 2.07 & $* 81 \%(\mathrm{H})$ & 1 & *U6687I \\
\hline $\begin{array}{l}\text { Unknown clone, homologous to Homo } \\
\text { sapiens clone *KIAA05I3 (u) }\end{array}$ & 13.21 & $* 81 \%(\mathrm{H})$ & 1 & *NM_0I4732 \\
\hline $\begin{array}{l}\text { Unknown clones (kc2668, kc522, kc2469) } \\
\text { (u) }\end{array}$ & 3 & & 3 & \\
\hline
\end{tabular}

Possible involvement: (tr), transcriptional; $(\mathrm{tl})$, translational; $(\mathrm{s})$, signalling; $(\mathrm{m})$ etabolic; $(\mathrm{u})$ unknown. Accession \# refers to porcine gene or close homologue: $(S)$ = sus scrofa, $R)=$ rattus norvegicus, $(B)=$ bos taurus, $(H)=$ homo sapiens, $(T)=$ tragelaphus buxtoni, $(P)$ physeter catodon, $(M)=$ mus musculus, $(O)=$ oryctolagus cuniculus, $(C)=$ canis domesticus, $(A)=$ ovis aries. 
Table 2: Genes more highly expressed in LD than in psoas

\begin{tabular}{|c|c|c|c|c|}
\hline Gene & LD/Psoas & Homology & \# of clones & Accession \# \\
\hline \multicolumn{5}{|l|}{ Mitochondrial origin } \\
\hline Ribosomal protein L35A & 2.2 & $86 \%(H)$ & 1 & AK055653 \\
\hline Ribosomal protein L7a & 1.85 & $90 \%(\mathrm{H})$ & 1 & $\mathrm{BC} 005 \mathrm{I} 28$ \\
\hline Ribosomal protein $\mathrm{S} 23$ & 1.91 & $88 \%(R)$ & i & $\times 77398$ \\
\hline Ribosomal protein SI2 & 1.61 & $100 \%(S)$ & 1 & $X 79417$ \\
\hline \multicolumn{5}{|l|}{ Sarcomeric / structural } \\
\hline Myosin heavy chain fast $2 a$ & 1.91 & $100 \%(S)$ & 6 & $A B 025260$ \\
\hline Myosin heavy chain fast $2 x$ & 1.77 & $100 \%(S)$ & 2 & $A B 025262$ \\
\hline Myosin heavy chain fast $2 b$ & 1.88 & $97 \%(S)$ & 2 & $A B 02526 I$ \\
\hline Myosin regulatory light chain 2 & 2.95 & $91 \%(\mathrm{H})$ & 2 & AF36306I \\
\hline Alpha actinin 3 & 1.47 & $93 \%(\mathrm{H})$ & 2 & M86407 \\
\hline S-nexilin & 1.77 & $70 \%(H)$ & I & AK057954 \\
\hline Fast skeletal troponin C & 1.67 & $94 \%(O)$ & 1 & Y00760 \\
\hline Fast skeletal troponin $\mathrm{T}(\mathrm{TnT} 3)$ & 1.7 & $93 \%(B)$ & 3 & AB085599 \\
\hline Alpha-I skeletal actin (ACTAI) & 1.53 & $93 \%(\mathrm{H})$ & 2 & $\mathrm{BC} 012597$ \\
\hline Alpha-2 smooth muscle actin (ACTA2) & 1.62 & $96 \%(H)$ & 1 & BC0I7554 \\
\hline \multicolumn{5}{|l|}{ Non-sarcomeric } \\
\hline $\begin{array}{l}\text { Sarcoplasmic/endoplasmic reticulum calcium } \\
\text { ATPase I (SERCAI) (g) }\end{array}$ & 1.54 & $98 \%(S)$ & 3 & AY027797 \\
\hline Aldolase A (g) & 1.47 & $87 \%(\mathrm{H})$ & I & BC0I0660 \\
\hline Phosphoglycerate kinase $(\mathrm{g})$ & 1.48 & $88 \%(\mathrm{H})$ & 1 & V00572 \\
\hline Glyceraldehyde-3-phosphate dehydrogenase (g) & 1.53 & $100 \%(S)$ & 1 & X9425I \\
\hline Muscle pyruvate kinase (PKM2) (g) & 1.63 & $91 \%(\mathrm{H})$ & 1 & BC007952 \\
\hline Phosphoglucomutase isoform 2 (PGM) (g) & 1.81 & $94 \%(O)$ & 1 & M97664 \\
\hline Muscle glycogen phosphorylase (g) & 1.65 & $92 \%(O)$ & 2 & X04265 \\
\hline Adenylate kinase isozyme I (myokinase) (g) & 1.51 & $87 \%(S)$ & 1 & E03007 \\
\hline Calsequestrin (c) & 1.7 & $83 \%(C)$ & 2 & J03766 \\
\hline Polyubiquitin (tl) & 1.51 & $90 \%(A)$ & 1 & AF038I29 \\
\hline Bridging-integrator protein-I (bin l) (s) & 2.17 & $85 \%(H)$ & I & AF00I383 \\
\hline Myomegalin-like protein $(\mathrm{u})$ & 6.94 & $94 \%(H)$ & I & AB042557 \\
\hline Heat shock cognate protein (HSPA8) (u) & 1.77 & $93 \%(B)$ & 1 & $\times 53827$ \\
\hline $\begin{array}{l}\text { Unknown clone, homologous to Homo sapiens } \\
\text { clone HSPCO40 (u) }\end{array}$ & 2.08 & $86 \%(H)$ & 1 & $\mathrm{BC} 000810$ \\
\hline $\begin{array}{l}\text { Unknown clone, homologous to 3' UTR of } \\
\text { Homo sapiens *actin bundling protein }(\mathrm{u})\end{array}$ & 1.99 & $* 77 \%(\mathrm{H})$ & 1 & *U09873 \\
\hline
\end{tabular}

Associated or possible role: (g), glycolysis; (c), contraction; ( $\mathrm{tl}$ ), translation; (s), signalling; (u) unknown. Accession \# refers to porcine gene or close homologue. Genus abbreviations as in Table I.

microarray analysis to be more highly expressed in the psoas than in the LD (Table 1), was individually quantified in 4 pigs (Fig. 4A). CK2 phosphorylation sites were also predicted in the deduced kc2725 protein (data not shown). All 4 pigs gave the same pattern of expression as that detected on the microarray. Interestingly, expression of kc2725 was ubiquitous and was much more abundant in other tissues than in skeletal muscle (Fig. 4B).

However, the expression of a gene from the same muscle can vary between similar individuals (Fig. 4A and Fig. 5A). Bin 1 was identified by microarray analysis as being more highly expressed in the LD than in the psoas (Table 3). However, this pattern of expression was found in only 3 out of 4 pigs (Fig. 5A). In pig 2, there was no significant difference in bin 1 expression between $\mathrm{LD}$ and psoas. Bin 1 was previously found to be ubiquitously expressed by Northern analysis $[18,21]$. Quantitative PCR showed that bin 1 expression was between 1 to 2 orders of magnitude greater in the heart and brain than in skeletal muscles (Fig. $5 \mathrm{~B})$. Therefore, TaqMan real-time quantitative PCR on selected representative genes had (1) demonstrated the functional integrity of our newly constructed porcine cDNA microarray in the appropriate identification of differentially expressed genes between red and white muscles, and (2) highlighted the existence of variation in muscle gene expression among similar individuals.

\section{Discussion}

Development of porcine skeletal muscle cDNA microarray We have constructed a composite porcine skeletal muscle cDNA microarray consisting of 5,500 clones from two de- 


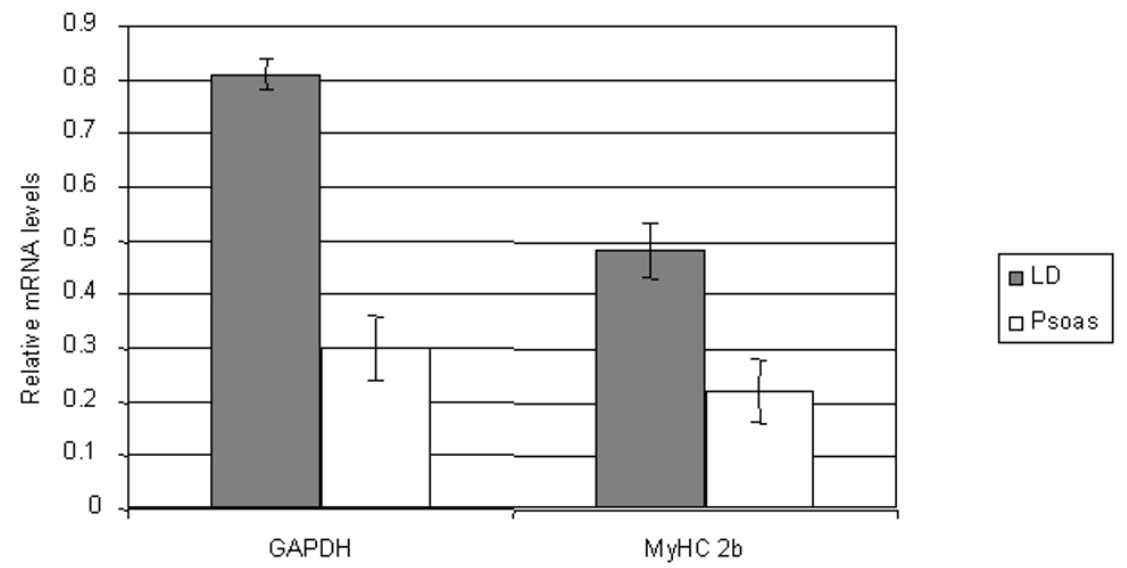

Figure 3

TaqMan quantitative real-time RT-PCR analysis of GAPDH, and MyHC $2 b$ mRNAs in porcine psoas (red) and LD (white) muscles. Results of pooled total cDNA samples from three 22-week-old Berkshire pigs. GAPDH and MyHC $2 \mathrm{~b}$ were about 2.7 and 2.5 times more highly expressed in the LD than psoas, respectively. Error bar $=$ standard deviation.

velopmentally distinct libraries, one derived from a 50day foetal longissimus dorsi muscle, and the other derived from a 3-day-old gastrocnemius muscle. The choice of two developmentally distinct libraries was to increase the range of temporally-regulated genes represented in the microarray, to extend its suitability for use in different microarray-based muscle experiments.

The selection emphasis for inclusion on the microarray was on lowly or moderately expressed clones. This clone selection reduced the representation of highly expressed genes, such as those encoding for sarcomeric proteins, and increased the likelihood of including rare transcripts, including those of regulatory importance. An alternative method of normalising clone selection, which has been used by others, is by reassociation of single-stranded library plasmids at relatively low $\mathrm{C}_{\mathrm{Ot}}$ to remove highly expressed clones [22,23]. Another commonly used and commercially available method of selection normalisation is subtractive suppression hybridisation [24]. We chose not to use this method for microarray clone selection because of the possibility of excluding lowly expressed non-muscle specific clones.

A possible disadvantage of our porcine microarray, at least at the beginning, is the lack of knowledge of the identity of each clone. However, there is, at present, insufficient sequence information on farm animals to design a comprehensive oligonucleotide-based microarray. To date, we have sequenced about $10 \%$ of our microarray clones (data not shown). A major advantage of our microarray is that we are likely to be in possession of the corresponding full length cDNA clones, whose inserts were unidirectionally cloned into a CMV-promoter driven expression plasmid ( $\mathrm{pBK}-\mathrm{CMV}$ vector). These clones could be readily used for downstream expression studies. As the identity of each clone is unknown, we do not know for certain how representative is the porcine skeletal muscle cDNA microarray. On the one hand, considering that there might be fewer than 30,000 human genes [25], and assuming that $50 \%$ of all genes are transcriptionally active at one time in a given tissue [26], it is possible that around $20 \%$ of the genes that are expressed in skeletal muscle are found on our microarray $[25,27]$. On the other hand, a group of 4080 human skeletal muscle genes, which included both skeletal muscle-specific genes and genes expressed in skeletal muscle as well as in other tissues, was found to correspond to $80 \%$ of the total number of genes expressed in skeletal muscle as reported so far in Unigene (including foetal muscle and rhabdomyosarcoma) [26]. Hence our microarray may represent substantially more than $20 \%$ of all genes expressed in porcine muscle. 
A.

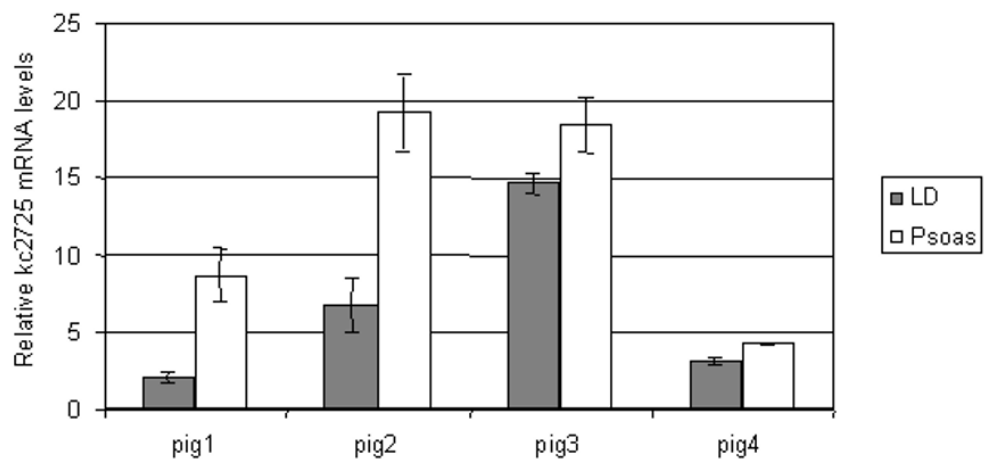

B.

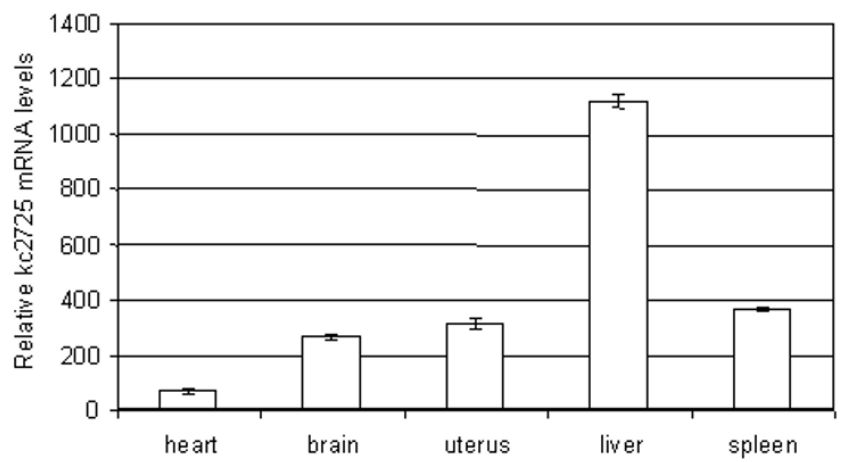

\section{Figure 4}

Tissue distribution of a novel gene kc2725. A. Expression of kc2725 was higher in the psoas than in the LD in all 4 pigs. Pigs I to 3 were 22-week-old Berkshires, and pig 4 was a 7-week-old cross breed. B. The expression of kc2725 was ubiquitous and much more abundant in other tissues. Error bar = standard deviation.

\section{Differential gene expression in red and white muscles} One objective of the red-white muscle experiment was simply to test the function of the newly assembled porcine microarray, from which two gene lists were generated (Tables 1 and 2). Genes that were expected to be differentially expressed and genes that were novel were found on each list. The microarray results validated our prior hypothesis of differential gene expression in red and white muscles, thus demonstrating the functional integrity of our newly constructed microarray. One of the well established distinguishing features of red muscle is its relatively high oxidative phosphorylation capacity, reflected by an abundance of mitochondria in red muscles. It is reassuring that genes from the mitochondrial genome were well represented in the red muscle pool of differentially expressed genes (Table 1). White muscles comprise predominantly more fast-glycolytic fibres than red muscles. Our findings were consistent with expectations, in that most of the 45 clones selected as more highly expressed in white muscle (Table 2) were either fast isoforms of structural genes, or enzymes connected with anaerobic glycolysis. With highly expressed genes, such as mitochondrial genes and structural genes, there were detectable levels of redundancies (repeats) on the microarray. However, in the presence of redundancies, no gene was found to be present on both lists. Differentially expressed clones originating from both the foetal and neonatal libraries were found in comparable proportion (data not shown). A recent report comparing red and white murine skeletal muscles on generic commercial oligonucleotide chips (Affymetrix 
A.

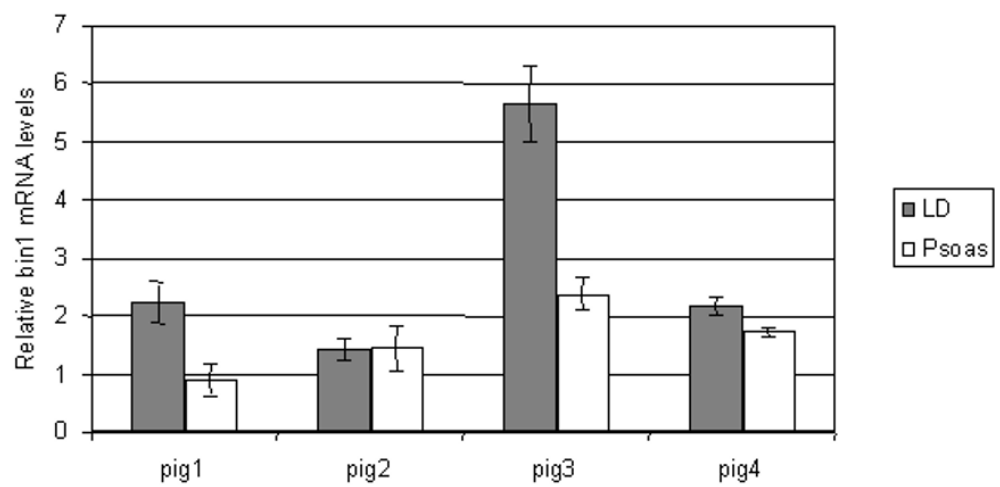

B.

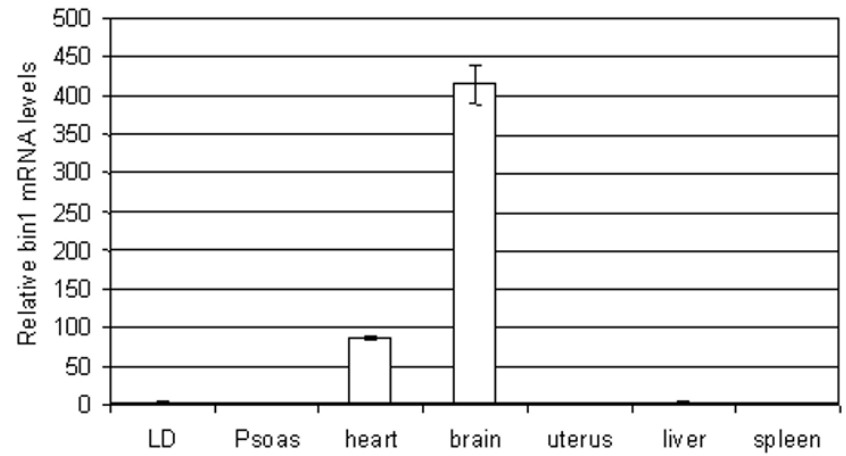

\section{Figure 5}

Bin I mRNA expression detected by TaqMan quantitative real-time RT-PCR. A. In pigs I, 3 and 4, bin I mRNA was more abundant in the LD than in the psoas. In pig 2, bin I expression in both muscles was similar. Pigs I to 3 were 22-week-old Berkshires, and pig 4 was a 7 -week-old cross breed. B. Although ubiquitous, bin I expression was by far most abundant in the brain and heart. Error bar = standard deviation.

GeneChips), which comprised the equivalent of 3,000 different genes, yielded a differential list of 49 known genes [28]. Our results of known differentially expressed genes were comparable in both number and in the different types of genes found.

One problem underlying the analysis of microarray data is the large number of comparisons required, which can produce false positive results [29]. We compared the expression of clones in psoas and LD muscle as the median of 14 comparisons (each microarray clone was printed twice on each slide and 7 slides were used), and restricted further analysis to the clones demonstrating the most consistent and extreme differences. Therefore, the majority of our identified clones are likely to represent real differences between muscles. However, any specific gene assignment should be regarded as provisional until it can be confirmed in an independent study, such as another microarray or in another assay such as quantitative PCR.

The interpretation of microarray results can be complicated. Firstly, members of the same gene family could crosshybridise to the same spots on the microarray. Interpretation of differential expression of individual isoforms should therefore be made with caution. In the case of MyHC genes (Table 2), a plausible interpretation is that fast MyHC mRNA isoforms (2a, 2x and 2b) were more abundant in the LD than in the psoas. However, we have 
Table 3: Oligonucleotides and TaqMan fluorogenic probes

\begin{tabular}{lll}
\hline Gene & Primer & Sequence $5^{\prime} \rightarrow 3^{\prime}$ \\
\hline \multirow{2}{*}{-actin } & S & CCA GCA CCA TGA AGA TCA AGA TC \\
& A & ACA TCT GCT GGA AGG TGG ACA \\
GAPDH & Ps & CCC CTC CCG AGC GCA AGT ACT CC \\
& S & AGG CTC GGG CTC ACT TGA A \\
MyHC 2b & A & TGC CCA TCA CAA ACA TGG G \\
& Ps & AGC CAA AAG GGT CAT CAT CTC TGC CC \\
Binl & S & CAC TTT AAG TAG TTG TCT GCC TTG AG \\
& As & GGC AGC AGG GCA CTA GAT GT \\
Novel gene (kc2725) & TGC CAC CGT CTT CAT CTG GTA ACA TAA GAG G \\
& A & GCC AGC AAT GTG CAG AAG AA \\
& Pa & CAT CTG CCT TCC CCA GTT TC \\
& S & CCT TCT CCT GCG CGC GAG TGA G \\
& ATT TTT CCA TTC CCT GGT TGA \\
& Ps & AGG GAC CCT GTA AGC CAA CA \\
\end{tabular}

$\mathrm{S}$, sense; $\mathrm{A}$, antisense, $\mathrm{Ps}$, TaqMan sense probe; $\mathrm{Pa}$, TaqMan antisense probe

previously found by quantitative real time RT-PCR that in at least 4 out of 6 pigs, of the same sex, age and breed as the one used in the microarray hybridisation, MyHC 2a and $2 \mathrm{x}$ were, in fact, more highly expressed in the psoas than in the LD [20]. The 3 fast MyHC isoforms found in Table 2 might have been the result of cross hybridisation by the relatively large amounts of MyHC $2 \mathrm{~b}$ specific probe generated from the LD muscle. Secondly, in comparing the profiles of two normal physiological states, such as red and white muscles, large variation in normal gene expression between individual pigs could present a major problem [30]. This variation is mainly attributed to genetic differences that exist between individual pigs; even pigs of the same breed are not genetically the same. The use of pooled porcine mRNA samples could inadvertently increase the genetic variation within each experimental group of animals. Therefore, in the context of porcine redwhite muscle microarray analysis, there may be no advantage in pooling mRNAs, derived from the same muscle of several pigs. On the other hand, the use of different muscles from the same pig could minimise the effects of environmental variation, which could exist between individuals. The use of inbred lines in laboratory rodents largely eliminates the problem of genetic variation between individuals of the same line. Hence, the use of labelled cDNA from pooled inbred individuals would enhance experimental reliability without increasing genetic variation. However, inbred pig strains are not widely available and limited to a few lines of mini-pigs. Whether the microarray probes were derived from an individual or pooled from a group of individuals, extensive validation, such as by quantitative PCR or Northern analysis, is necessary to demonstrate that the differential expression of a gene identified on a microarray is consistent in a wider context.

\section{Candidate genes for phenotype determination}

From the red-white muscle microarray results, a list of novel candidate regulatory genes that could influence muscle phenotype, such as hypertrophy, differentiation and isoform-specific expression, was identified. Most of the genes listed as unknown (Table 1 and 2) were found with major open-reading frames, suggesting that they code for protein products. Candidate regulatory genes with putative identities were based on homology comparison. Even for these genes, with the possible exception of bin1, their functional roles in skeletal muscle are largely unclear. CK2 $\alpha 1$ subunit, smpx, and tyrosine kinase A6-related gene are particularly interesting. They were found to be more highly expressed in red muscle and are connected to the casein kinase 2 signalling pathway. CK2 is a serine/ threonine kinase that has been implicated in cell growth and proliferation [31,32]. CK2-mediated phosphorylation of Myf-5, a member of a family of myogenic transcription factors, was reported to be required for Myf-5 activity [33]. Presently, the contribution of the CK2 signalling pathway to skeletal muscle function is not known. Its role in muscle phenotype determination requires further evaluation. The gene for heat shock $70 \mathrm{kD}$ protein 8 (HSPA8) seemed to be upregulated in white muscle. Heat shock proteins are considered to be molecular chaperones and indicators of cellular stress [34]. The same gene was found to be upregulated in human hypertrophic cardiomyopathy [35]. It is not clear if this finding was related to cellular stress of myopathy or muscle hypertrophy. 
Our results demonstrate the power of microarray analysis in identifying candidate genes that influence muscle phenotype. The challenge now is to confirm these associations and demonstrate how these genes are involved in the relevant muscle phenotypes.

\section{Methods}

Construction of porcine skeletal muscle cDNA microarray Mass phagemid excision was performed on two porcine skeletal muscle $\lambda$ ZAP-Express CDNA libraries (50-day foetal longissimus dorsi muscle and 3-day-old gastrocnemius muscle), developed in-house, according to manufacturer's protocol (Stratagene). Both libraries, each with a million primary plaques, had been extensively characterised by sequencing and screening, and were used to isolate several full-length cDNA clones, including MyHCs $(6.0 \mathrm{~kb}$ in size) and transcription factors, such as NFAT2 and GATA2. One study, performed on adult human skeletal muscle, found that highly expressed genes represented only $9.1 \%$ of the transcript variation, whereas moderately and weakly expressed genes made up $27.5 \%$ and $63.5 \%$ of the variation, respectively [26]. In order to ensure that the clones chosen for the porcine microarray assembly represented as many different genes as possible, clones were screened by colony hybridisation to assess their relative abundance of expression. About 400 bacterial clones were picked onto each square agar plate (Bio-Assay dish, Nunc) for colony hybridisation with ${ }^{32} \mathrm{P}$-labelled cDNA probe, derived from mRNA extracted by oligo $(\mathrm{dT})_{25}$ Dynabeads (Dynal) from the same muscle type and stage of development as that used for the library construction. Based on signal intensity on the autoradiograms, each clone was classified as a weakly, moderately or highly expressed gene [26]. Clones picked for microarray construction were judged to be lowly or moderately expressed. Miniprep plasmid DNA was prepared from selected clones using the QIAprep 96 Turbo kit (Qiagen).

Insert amplification of each pBK-CMV-based plasmid clone (Stratagene) was performed with T7 primer (5'-GTA ATA CGA CTC ACT ATA GGG C-3') and T3 primer (5'CGA AAT TAA CCC TCA CTA AAG GG-3'), using a HotStarTaq Master Mix kit (Qiagen). PCR was conducted in a $100 \mu \mathrm{l}$ volume, using the equivalent of $0.1 \mu \mathrm{l}$ of miniprep plasmid (about $15 \mathrm{ng}$ ), for 35 cycles at $55^{\circ} \mathrm{C}$ for $45 \mathrm{~s}$, followed by $72^{\circ} \mathrm{C}$ for $3.5 \mathrm{~min}$, and $94^{\circ} \mathrm{C}$ for $1 \mathrm{~min}$, with an initial activation step of $95^{\circ} \mathrm{C}$ for 15 min. PCR products were purified with QIAquick 96 PCR Purification kit (Qiagen) and printed onto CMT-GAPS coated slides (Corning) using a Microgrid II arraying robot (BioRobotics, Cambridge, UK). Spotted DNA was immobilised by baking at $80^{\circ} \mathrm{C}$ for two hours. Each clone was printed in duplicate on each slide. Appropriate positive controls to help with orientation and vector controls were incorporated on the microrarray.

\section{Red-white muscle microarray hybridisation}

Messenger RNA was extracted by oligo(dT $)_{25}$ Dynabeads (Dynal) from the longissimus dorsi (LD), a white muscle, and the psoas, a red muscle, of a 22-week-old pig (Berkshire breed). Dual Cy-dye labellings were performed with a CyScribe First-Strand cDNA labelling kit (Amersham), which incorporates the use of oligo(dT) primers and random nanomers. Labelled cDNAs were purified in AutoSeq G-50 columns (Amersham). In a typical Cy3 or Cy5 labelling reaction, using 0.5 to $1.0 \mu \mathrm{g}$ mRNA, a final volume of $32 \mu \mathrm{l}$ was obtained, which was used on two microarray slides. Prior to pre-hybridisation, microarray slides were denatured in distilled water by heating to $95^{\circ} \mathrm{C}$ for $2 \mathrm{~min}$. Pre-hybridisation was then performed in a plastic 2-slide holder containing $15 \mathrm{ml}$ of $3 \times$ SSC (sodium chloride and sodium citrate), $\%$ bovine serum albumin (B4287, Sig$\mathrm{ma}$ ) and $0.1 \% \mathrm{SDS}$ at $65^{\circ} \mathrm{C}$ for $20 \mathrm{~min}$. After a brief rinse in distilled water at room temperature, the slides were dehydrated in absolute ethanol and centrifuged at $100 \mathrm{~g}$ for $2 \mathrm{~min}$.

Labelled probe was not quantified. Equal volumes of Cy3 and Cy5 labelled probes (16 $\mu \mathrm{l}$ each) were mixed with 1.0 $\mu \mathrm{l}(8.0 \mu \mathrm{g} / \mu \mathrm{l})$ of poly(dA) oligonucleotide (27-7836, Amersham), heated to $95^{\circ} \mathrm{C}$ for $2 \mathrm{~min}$, and mixed with 33 $\mu$ l of $2 \times$ hybridisation buffer (GHB-200, Genpak). A microarray slide was layered with the hybridisation mixture, then covered with a $22 \mathrm{~mm} \times 64 \mathrm{~mm}$ cover glass (BDH), to the exclusion of air bubbles, and placed in a hybridisation chamber (Arraylt hybridisation cassette AHC-1) in a $45^{\circ} \mathrm{C}$ dry incubator for $24 \mathrm{~h}$. Slides were washed once in $300 \mathrm{ml}$ of $1 \times$ SSC and $0.2 \%$ SDS for 10 min at $45^{\circ} \mathrm{C}$, twice in $300 \mathrm{ml}$ of $0.2 \times$ SSC and $0.2 \%$ SDS for $10 \mathrm{~min}$ at $45^{\circ} \mathrm{C}$, and twice in $300 \mathrm{ml}$ of $0.1 \times$ SSC for $10 \mathrm{~min}$ at $37^{\circ} \mathrm{C}$. After drying in a centrifuge at $100 \mathrm{~g}$ for 2 min, scanning was performed with an Affymetrix 428 scanner. A total of seven microarray slides (replicates) were subjected to two-colour Cy-dye hybridisation and scanned for the red-white muscle experiment.

\section{Microarray expression analysis and clone identification}

Image analysis (grid generation and dye quantification) of scanned slides was performed with ImaGene v4.2 (BioDiscovery). Data mining was conducted with GeneSpring v4.2 (Silicon Genetics), in which 3 normalisation steps were performed: per spot, intensity-dependent, and per chip (slide). In per spot normalisation, after background subtraction, the fluorescent intensity (e.g. Cy3) of each clone was divided by its control or reference channel intensity (e.g. Cy5). Values of the control channel that fell below 10 were adjusted to 10 prior to taking the ratio between signal and control value. Intensity-dependent (non-linear or LOWESS) normalisation was applied to correct for artefacts caused by differential Cy3 and Cy5 dye incorporation and non-linear rates of fluorescence be- 
tween the two dyes. Per chip normalisation was used to take into account intensity variation across the entire slide, by dividing the signal strength of a clone on a slide by the $50^{\text {th }}$ percentile signal of all of the measurements taken from the same slide. Additionally, the GeneSpring Global Error Model, based on the replicate measurement samples of all genes on the microarray was used to estimate differences between medians, the standard errors among the different clones, and the extreme tails of the distribution of differences. Differences among muscles in expression were standardised for different clones by dividing the difference between muscle medians by the square root of the common variance. Sequencing reactions with T7 and T3 primers were conducted with an ABI BigDye Terminator v3.0 PCR-based sequencing kit (Applied Biosystems). Performa DTR gel filtration cartridges (EDGE Biosystems) were used for purification of PCR products prior to loading onto the ABI PRISM 3100 Genetic Analyzer. All sequence data were subjected to BLAST (Basic Local Alignment Search Tool) searches for gene identification by sequence similarity.

\section{Quantitative real-time RT-PCR}

Quantitative real-time RT-PCR was performed using TaqMan (Applied Biosystems) on five selected porcine genes: $\beta$-actin, GAPDH, MyHC $2 \mathrm{~b}$, bin 1 , and a novel gene (kc2725) (Table 3). The protocol, based on the use of the relative standard curve, was as previously described [20]. In the relative standard curve method of quantification, comparisons of relative expression should only be made between samples of the same gene. It is not appropriate to compare expression levels between two different genes. A reference cDNA panel, comprising a number of different tissue templates (LD muscle, psoas, heart, uterus, brain, liver and spleen) of a 7-week-old pig, along with LD and psoas cDNAs, from three additional 22-week-old Berkshire pigs, were used to evaluate the quantitative distribution of selected genes.

\section{Authors' contributions}

QB generated the microarray clones. CM, NdC, MJM and KCC helped with the validation and analysis of the microarray. DS and GE were responsible for the production of the microarray and advised on its experimental use. KCC conceived the study and was responsible for writing the manuscript. All authors read and approved the final manuscript.

\section{Acknowledgements}

This work was supported by a scholarship from the University of Glasgow to QB, by Sygen International and by the BBSRC.

\section{References}

I. Pette D and Staron RS Cellular and molecular diversities of mammalian skeletal fibers Rev Physiol Biochem Pharmacol 1990, I 16:2-76
2. Schiaffino $S$ and Reggiani $C$ Molecular diversity of myofibrillar proteins: Gene regulation and functional significance Physiol $\operatorname{Rev}$ 1996, 76:37I-423

3. Schiaffino $S$ and Reggiani $C$ Myosin isoforms in mammalian skeletal muscle J Appl Physiol 1994, 77:493-50 I

4. Weiss $A$ and Leinwand LA The mammalian myosin heavy chain gene family Annu Rev Cell Dev Biol 1996, 1 2:417-439

5. Chang KC and Fernandes $K$ Developmental expression and 5' end CDNA cloning of the porcine $2 x$ and $2 b$ myosin heavy chain genes DNA Cell Biol 1997, 16:1429-1437

6. Chang KC, Fernandes K and Dauncey MJ Molecular characterization of a developmentally regulated porcine skeletal myosin heavy chain gene and its $\mathbf{5}^{\prime}$ regulatory region J Cell Sci 1995, 108: 1779-1789

7. Chang $K C$, Fernandes $K$ and Goldspink $G$ In vivo expression and molecular characterization of the porcine slow-myosin heavy chain J Cell Sci 1993, 106:331-34I

8. Klont RE, Brocks $L$ and Eikelenboom $G$ Muscle fibre type and meat quality Meat Sci 1998, 49:S219-S229

9. Karlsson $\mathrm{AH}, \mathrm{Klont} \mathrm{RE}$ and Fernandez $X$ Skeletal muscle fibres as factors for pork quality Livest Prod Sci 1999, 60:255-269

10. Essén-Gustavsson $B$ Muscle-fiber characteristics in pigs and relationships to meat-quality parameters- review Pork quality: genetic and metabolic factors (Edited by: PuolanneE and DemeyerDI) Wallingford UK, CAB International 1993, I40-159

II. Hughes SM and Schiaffino S Control of muscle fibre size: a crucial factor in ageing Acta Physiol Scand 1999, 167:307-312

12. Larsson $L$ and Ramamurthy $B$ Aging-related changes in skeletal muscle Drugs Aging 2000, 4:303-316

13. Duggan DJ, Bittner M, Chen Y, Meltzer $P$ and Trent JM Expression profiling using cDNA microarrays Nat Genet 1999, 2 1:10-14

14. Blanquet PR Casein kinase 2 as a potentially important enzyme in the nervous system Prog Neurobiol 2000, 60:21I-246

15. Faust $M$ and Montenarh $M$ Subcellular localization of protein kinase CK2. A key to its function? Cell Tissue Res 2000, 30 I:329-340

16. Kemp TJ, Sadusky TJ, Simon M, Brown R, Eastwood M, Sassoon DA and Coulton GR Identification of a novel stretch-responsive skeletal muscle gene (Smpx) Genomics 200I, 72:260-27I

17. Rohwer A, Kittstein W, Marks F and Gschwendt M Cloning, expression and characterization of an A6-related protein Eur J Biochem 1999, 263:518-525

18. Sakamuro D, Elliot KJ, Wechsler-Reya R and Prendergast GC Bin I is a novel Myc-interacting protein with features of a tumour suppressor Nat Genet 1996, 14:69-77

19. Wechsler-Reya RJ, Elliot $\mathrm{KJ}$ and Prendergast GC A role for the putative tumor suppressor bin $I$ in muscle cell differentiation Mol Cell Biol 1998, I 8:566-575

20. da Costa N, Blackley R, Alzuherri $\mathrm{H}$ and Chang KC Quantifying the temporo-spatial expression of porcine postnatal skeletal myosin heavy chain genes ] Histochem Cytochem 2002, 50:353-364

21. Tsutsui K, Maeda Y, Seki S and Tokunaga A cDNA cloning of a novel amphiphysin isoform and tissue-specific expression of its multiple variants Biochem Biophy Res Com 1997, 236:178-183

22. Rink $A$, Santschi $M$ and Beattie CW Normalized cDNA libraries from a porcine model of orthopedic implant-associated infection Mammal Genome 2002, 1 3: | 98-205

23. Soares MB, Bonaldo MF, Jelene $P$, Su L, Lawton $L$ and Efstratiadis $A$ Construction and characterization of a normalized cDNA library Proc Natl Acad Sci U S A 1994, 9 I:9228-9232

24. von Stein OD Isolation of differentially expressed genes through subtractive suppression hybridization Genomics protocols (Edited by: StarkeyMP and ElaswarapuR) Totowa, Human Press Inc. 200I, 263-278

25. Venter JC, Adams MD, Myers EW, Li PW, Mural RJ, Sutton GG, Smith HO, Yandell M, Evans CA, Holt RA, Gocayne JD, Amanatides Peter, Ballew Richard M., Huson Daniel H., Wortman Jennifer Russo, Zhang Qing, Kodira Chinnappa D., Zheng Xiangqun H., Chen Lin, Skupski Marian, Subramanian Gangadharan, Thomas Paul D., Zhang Jinghui, Gabor Miklos George L., Nelson Catherine, Broder Samuel, Clark Andrew G., Nadeau Joe, McKusick Victor A., Zinder Norton, Levine Arnold J., Roberts Richard J., Simon Mel, Slayman Carolyn, Hunkapiller Michael, Bolanos Randall, Delcher Arthur, Dew lan, Fasulo Daniel, Flanigan Michael, Florea Liliana, Halpern Aaron, Hannenhalli Sridhar, Kravitz Saul, Levy Samuel, Mobarry Clark, Reinert Knut, Remington Karin, Abu-Threideh Jane, Beasley Ellen, Biddick Kendra, Bonazzi Vivien, Brandon Rhonda, Cargill Michele, Chandramouliswaran Ishwar, 
Charlab Rosane, Chaturvedi Kabir, Deng Zuoming, Francesco Valentina Di, Dunn Patrick, Eilbeck Karen, Evangelista Carlos, Gabrielian Andrei E., Gan Weiniu, Ge Wangmao, Gong Fangcheng, Gu Zhiping, Guan Ping, Heiman Thomas J., Higgins Maureen E., Ji Rui Ru, Ke Zhaoxi, Ketchum Karen A., Lai Zhongwu, Lei Yiding, Li Zhenya, Li Jiayin, Liang Yong, Lin Xiaoying, Lu Fu, Merkulov Gennady V., Milshina Natalia, Moore Helen M., Naik Ashwinikumar K., Narayan Vaibhav A., Neelam Beena, Nusskern Deborah, Rusch Douglas B., Salzberg Steven, Shao Wei, Shue Bixiong, Sun Jingtao, Wang Zhen Yuan, Wang Aihui, Wang Xin, Wang Jian, Wei Ming Hui, Wides Ron, Xiao Chunlin, Yan Chunhua, Yao Alison, Ye Jane, Zhan Ming, Zhang Weiqing, Zhang Hongyu, Zhao Qi, Zheng Liansheng, Zhong Fei, Zhong Wenyan, Zhu Shiaoping C., Zhao Shaying, Gilbert Dennis, Baumhueter Suzanna, Spier Gene, Carter Christine, Cravchik Anibal, Woodage Trevor, Ali Feroze, An Huijin, Awe Aderonke, Baldwin Danita, Baden Holly, Barnstead Mary, Barrow lan, Beeson Karen, Busam Dana, Carver Amy, Center Angela, Cheng Ming Lai, Curry Liz, Danaher Steve, Davenport Lionel, Desilets Raymond, Dietz Susanne, Dodson Kristina, Doup Lisa, Ferriera Steven, Garg Neha, Gluecksmann Andres, Hart Brit, Haynes Jason, Haynes Charles, Heiner Cheryl, Hladun Suzanne, Hostin Damon, Houck Jarrett, Howland Timothy, Ibegwam Chinyere, Johnson Jeffery, Kalush Francis, Kline Lesley, Koduru Shashi, Love Amy, Mann Felecia, May David, McCawley Steven, Mclntosh Tina, McMullen Ivy, Moy Mee, Moy Linda, Murphy Brian, Nelson Keith, Pfannkoch Cynthia, Pratts Eric, Puri Vinita, Qureshi Hina, Reardon Matthew, Rodriguez Robert, Rogers Yu Hui, Romblad Deanna, Ruhfel Bob, Scott Richard, Sitter Cynthia, Smallwood Michelle, Stewart Erin, Strong Renee, Suh Ellen, Thomas Reginald, Tint Ni Ni, Tse Sukyee, Vech Claire, Wang Gary, Wetter Jeremy, Williams Sherita, Williams Monica, Windsor Sandra, Winn-Deen Emily, Wolfe Keriellen, Zaveri Jayshree, Zaveri Karena, Abril Josep F., Guigo Roderic, Campbell Michael J., Sjolander Kimmen V., Karlak Brian, Kejariwal Anish, Mi Huaiyu, Lazareva Betty, Hatton Thomas, Narechania Apurva, Diemer Karen, Muruganujan Anushya, Guo Nan, Sato Shinji, Bafna Vineet, Istrail Sorin, Lippert Ross, Schwartz Russell, Walenz Brian, Yooseph Shibu, Allen David, Basu Anand, Baxendale James, Blick Louis, Caminha Marcelo, Carnes-Stine John, Caulk Parris, Chiang Yen Hui, Coyne My, Dahlke Carl, Mays Anne Deslattes, Dombroski Maria, Donnelly Michael, Ely Dale, Esparham Shiva, Fosler Carl, Gire Harold, Glanowski Stephen, Glasser Kenneth, Glodek Anna, Gorokhov Mark, Graham Ken, Gropman Barry, Harris Michael, Heil Jeremy, Henderson Scott, Hoover Jeffrey, Jennings Donald, Jordan Catherine, Jordan James, Kasha John, Kagan Leonid, Kraft Cheryl, Levisky Alexander, Lewis Mark, Liu Xiangjun, Lopez John, Ma Daniel, Majoros William, McDaniel Joe, Murphy Sean, Newman Matthew, Nguyen Trung, Nguyen Ngoc, Nodell Marc, Pan Sue, Peck Jim, Peterson Marshall, Rowe William, Sanders Robert, Scott John, Simpson Michael, Smith Thomas, Sprague Arlan, Stockwell Timothy, Turner Russell, Venter Eli, Wang Mei, Wen Meiyuan, Wu David, Wu Mitchell, Xia Ashley, Zandieh Ali and Zhu Xiaohong The Sequence of the human genome Science 200I, 29 I:|304-I35I

26. Bortoluzzi S, d'Alessi F, Romualdi $C$ and Danieli GA The human adult skeletal muscle transcriptional profile reconstructed by novel computational approach Genome Res 2000, 10:344-349

27. Pietu G, Eveno E, Soury-Segurens B, Fayein NA, Mariage-Samson R, Matingou C, Leroy E, Dechesne C, Krieger S, Ansorge W, ReguigneArnould I, Cox D, Dehejia A, Polymeropoulos MH, Devignes MD and Auffray $C$ The genexpress IMAGE knowledge base of the human muscle transcriptome: a resource of structural, functional, and positional candidate genes for muscle physiology and pathologies Genome Res 1999, 9:1313-1320

28. Campbell WG, Gordon SE, Carlson CJ, Pattison JS, Hamilton MT and Booth FW Differential global gene expression in red and white skeletal muscle Am J Physiol -Cell Physiol 200I, 280:C763C768

29. Nadon R and Shoemaker J Statistical issues with microarrays: processing and analysis Trends Genet 2002, | 8:265-27|

30. Chang KC, da Costa N, Blackley R, Southwood O, Evans G, Plastow G, Wood JD and Richardson RI Relationships of myosin heavy chain fibre types to meat quality traits in traditional and modern pigs Meat Sci 2003 , in press:

31. Guerra B and Issinger OG Protein kinase CK2 and its role in celIular proliferation, development and pathology Electrophoresis 1999, 20:391-408

32. Tawfic S, Yu S, Wang H, Faust R, Davis A and Ahmed K Protein kinase CK2 signal in neoplasia Histol Histopathol 200I, 16:573-582
33. Winter B, Kautzner I, Issinger OG and Arnold HH Two putative protein kinase CK2 phosphorylation sites are important for Myf-5 activity Biol Chem 1997, 378: I 445-1456

34. Liu YF and Steinacker JM Changes in skeletal muscle heat shock proteins: pathological significance Front Biosci 200 I, 6: d I 2-d25

35. Lim DS, Roberts R and Marian AJ Expression profiling of cardiac genes in human hypertrophic cardiomyopathy: insight into the pathogenesis of phenotypes J Am Coll Cardiol 200I, 38: I 1751180

Publish with Bio Med Central and every scientist can read your work free of charge

"BioMed Central will be the most significant development for disseminating the results of biomedical research in our lifetime. "

Sir Paul Nurse, Cancer Research UK

Your research papers will be:

- available free of charge to the entire biomedical community

- peer reviewed and published immediately upon acceptance

- cited in PubMed and archived on PubMed Central

- yours - you keep the copyright

Submit your manuscript here:

http://www.biomedcentral.com/info/publishing_adv.asp
BioMedcentral 